\title{
Coisas que acontecem... A guerra no lraque, por David Hare
}

\section{Maria Helena Serôdio}

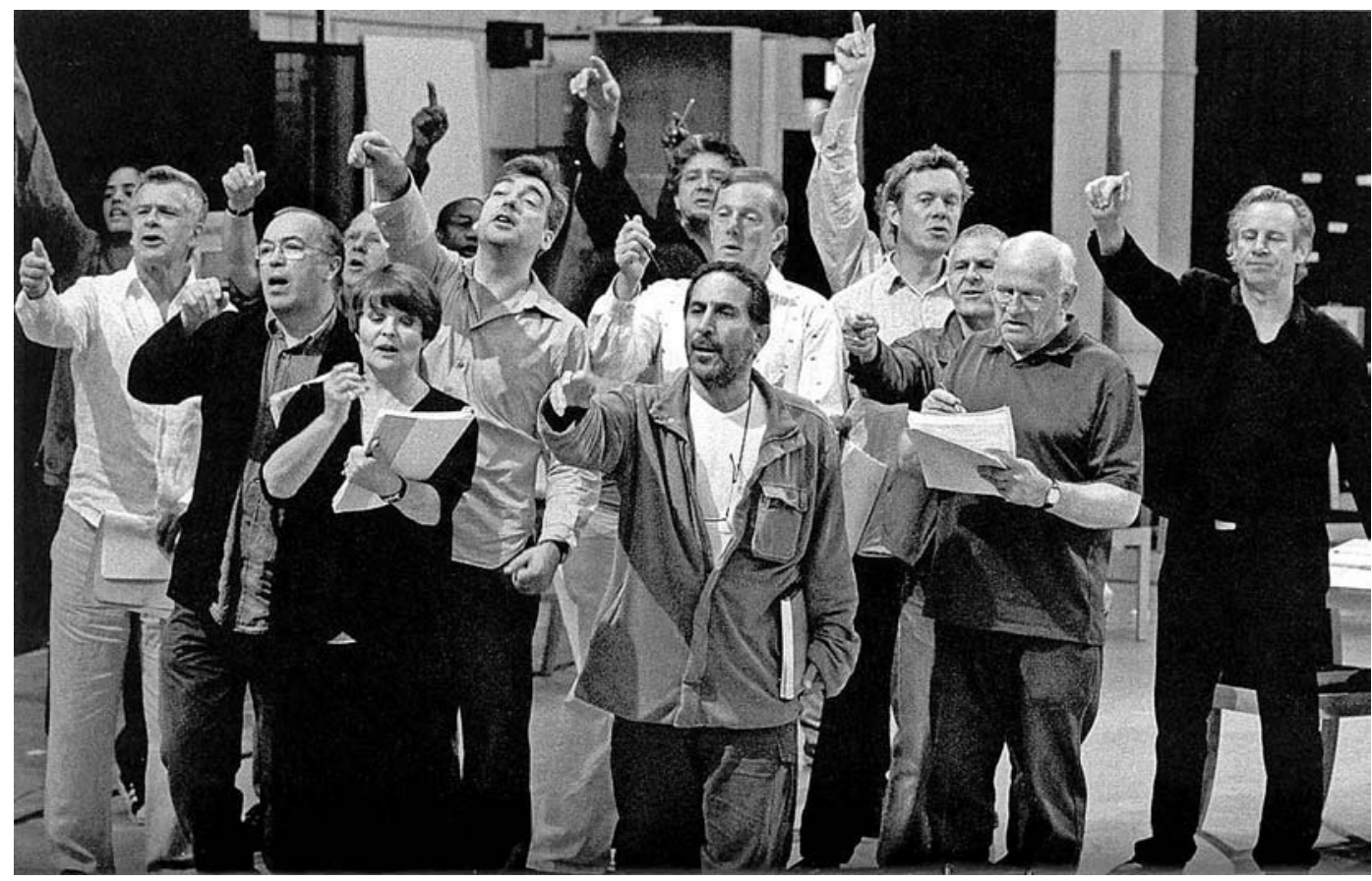

Titulo: Stuff Happens (São coisas que acontecem) (2004). Autor: David Hare. Encenação: Nicholas Hytner. Cenário: Christopher Oram. Desenho de luz: Paul Anderson. Som: Paul Groothuis. Música: Chostakovich (Quarteto de cordas N. o 8). Produção: National Theatre. Local e data de estreia: Londres, Sala Olivier, 10 de Setembro de 2004 (pré-estreias a partir do dia 1 de Setembro).

Apresentada como peça histórica sobre acontecimentos recentes, Stuff Happens (São coisas que acontecem) cita no título a frase - tristemente célebre - de Donald Rumsfeld quando Ihe pediram para comentar o saque de Bagdad na conferência de imprensa dada em 11 de Abril de 2003. A displicência chocante com que encarou o facto só por ironia amarga se encontrou com o termo - stuff - de que se serviu Próspero (Tempestade, IV, i, 156) para falar da evanescência da vida e da imponderabilidade da arte: "somos da matéria (stuff) de que são feitos os sonhos". Mas aqui, neste contexto do início do século XXI, será, afinal, de pesadelo que se trata.

Estreada a 10 de Setembro de 2004 na sala Olivier do Teatro Nacional, esta peça de David Hare resultou de um desafio do seu director - Nicholas Hytner - visando uma programação ousada para 2004 e foi considerada por muitos comentadores como "o grande acontecimento cultural do ano". 0 resultado de um trabalho sério de investigação documental ao serviço da criação artística foi um espectáculo notável que se tornou num fenómeno de popularidade, não apenas pelo público que atraiu (ávido de identificar as figuras políticas em cena e rendido ao calor do debate), mas também pela controvérsia que gerou. No centro da contestação estiveram, naturalmente, as questões políticas que a peça aborda de forma desassombrada, mas também a iniciativa que o jornal The Guardian promoveu de levar políticos, estadistas e outras personalidades da vida pública a ver o espectáculo (no âmbito reservado da préestreia), recolhendo as suas opiniões e publicando-as, antes mesmo que o seu crítico Michael Billington pudesse escrever sobre o espectáculo, comprometidos como estão os críticos a só publicarem a sua opinião depois da estreia.

Como autor de argumentos para televisão e cinema, David Hare será mais facilmente identificado pela sua recente intervenção no filme As horas (2002), sobre Virginia Woolf, adaptando à linguagem filmica o romance de Michael Cunningham. Mas da sua dramaturgia seis peças foram já encenadas em Portugal: Fanshen (Teatro Estúdio de Lisboa, 1976), Slag (Grupo Teatro Hoje, 1980), Luz de Inverno (Novo Grupo, 1998), The Blue Room (Teatro Taborda, 2002), Via dolorosa (Metamorfose Total, 2003) e My Zinc Bed (Metamorfose Total, 2004). 

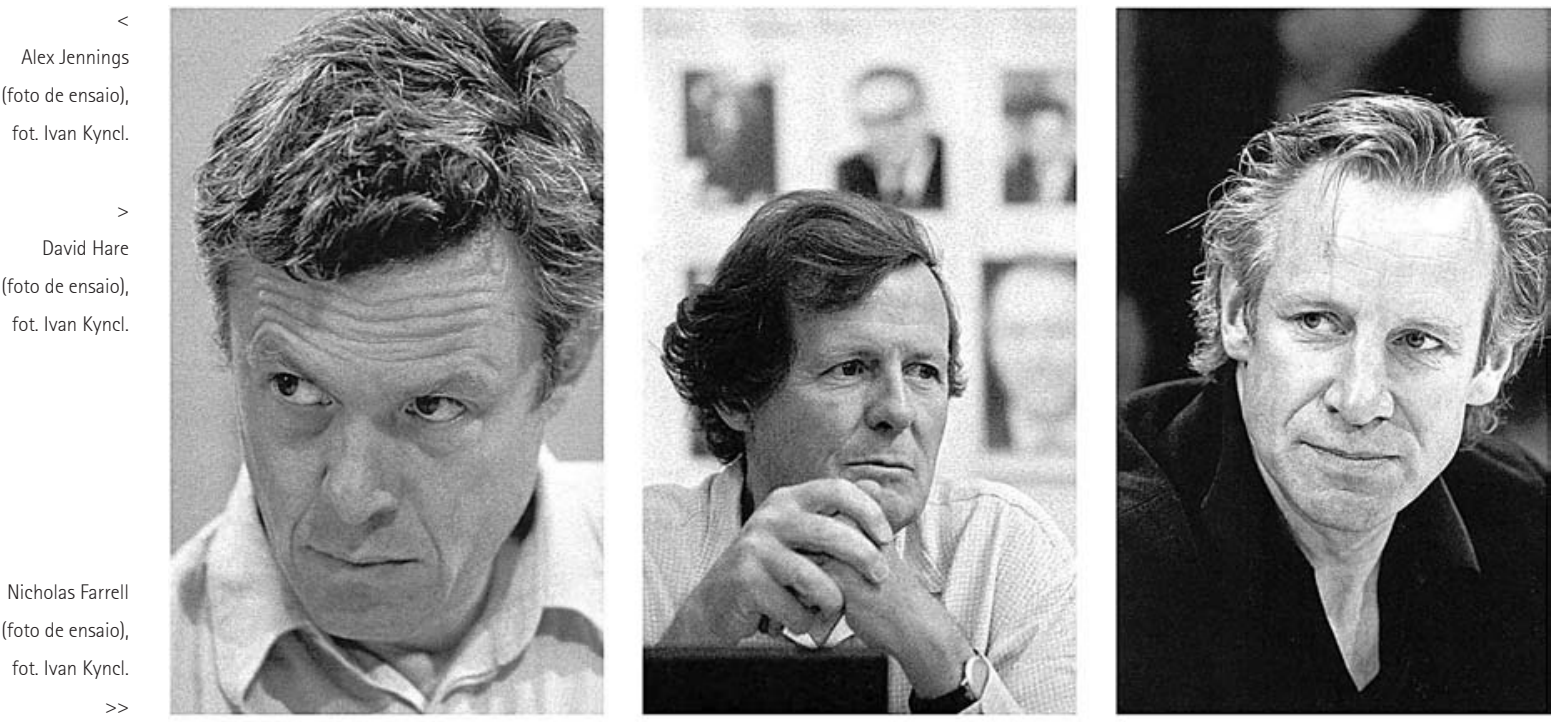

(foto de ensaio),

fot. Ivan Kyncl.
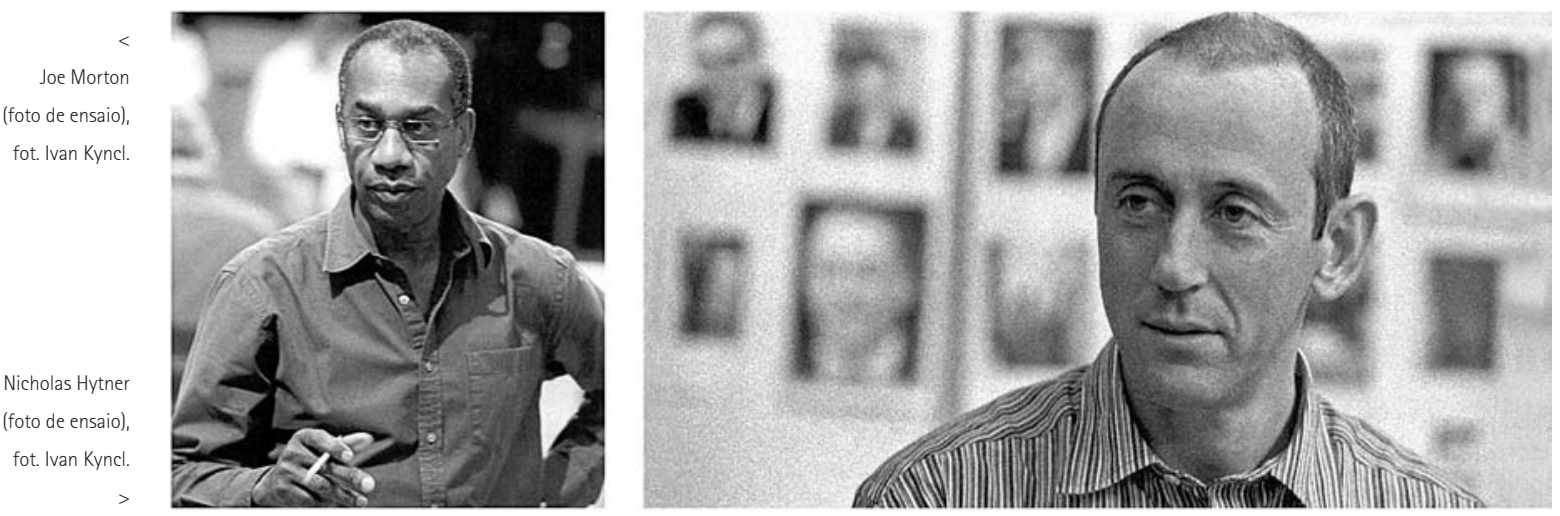

Ao seu nome está claramente associada a ideia de um teatro de intervenção, ainda que de perfil muito próprio, ligado, de uma maneira geral, mais a questões morais e psicológicas do que a claros pronunciamentos políticos e, do ponto de vista dramatúrgico, desenvolvendo com alguma perícia uma certa ambivalência na construção de personagens e acções. Talvez tenha sido essa a razão que Ihe terá valido a distinção do título nobiliárquico que recebeu da rainha em 1998, como comentaram os seus detractores, adiantando, porém, que já antes se "vendera" ao sistema político dominante tendo em vista os seus êxitos comerciais no West End e na Broadway. 0 que, todavia, não invalida o facto de alguns dos seus espectáculos continuarem a suscitar viva polémica, como foi o caso de Via dolorosa (sobre a questão palestiniana, que Hare escreveu e interpretou a solo) e agora esta evocação do desencadeamento da guerra do Iraque.

Integrando uma geração que em 1968 ocupou, de forma contestatária, a cena inglesa com grupos alternativos, Hare criou o Portable Theatre (com Tony Bicât, 1968) e o Joint Stock (este em conjunto com Max Stafford-Clark, 1973), passou pelo Royal Court Theatre como assessor literário e dramaturgo residente (1968-1971) e militou activamente na escrita de várias peças políticas em coautoria (com Howard Brenton). Em 1984, decidiu aceitar o convite de Peter Hall, então director do Teatro Nacional, para ser seu Director Associado, e nesse posto prosseguiu a sua ideia de incluir teatro político na programação do teatro inglês mais emblematicamente "central".
Todavia, se nunca se demitiu por inteiro de interrogar a política no seu teatro, a verdade é que num célebre discurso proferido em 1978 em Cambridge (a Universidade que Ihe conferira uma licenciatura em Estudos Ingleses, em 1968), Hare veio a denunciar com idêntico fervor combativo a ineficácia deste tipo de teatro para mobilizar consciências ou alterar radicalmente a situação política e social. Enfurecendo toda a esquerda e incompatibilizandose com o académico socialista que fora a sua grande referência teórica e o seu tutor na Universidade - Raymond Williams -, o dramaturgo manteve-se, porém, numa persistente atitude crítica relativamente ao sistema político inglês, denunciando a justiça, a Igreja, os partidos políticos e a imprensa (como no caso da trilogia que escreveu no início dos anos 90: Racing Demon, Murmuring Judges e The Absence of War) e exprimindo de forma nostalgicamente dorida a ideia de que a Inglaterra perdera já demasiadas oportunidades de se reformar ou redimir.

Em Stuff Happens, David Hare recuperou com rigor as exactas palavras de todos os intervenientes no processo: o topo da administração Bush, elementos destacados da ONU, bem como o seu parceiro europeu electivo, o governo de Blair. É evidente que algumas das conversas que decorreram à porta fechada são mais inventadas do que reportadas, mas não há dúvida de que há em toda a peça (e espectáculo) o estilo enérgico e vivo de uma reportagem televisiva (as notícias em primeira mão) e o fascínio de se contarem as histórias da História.

Tendo feito uma versão de Galileu, em 1994, para o Teatro Almeida e uma outra da Mãe Coragem para o Nacional, 


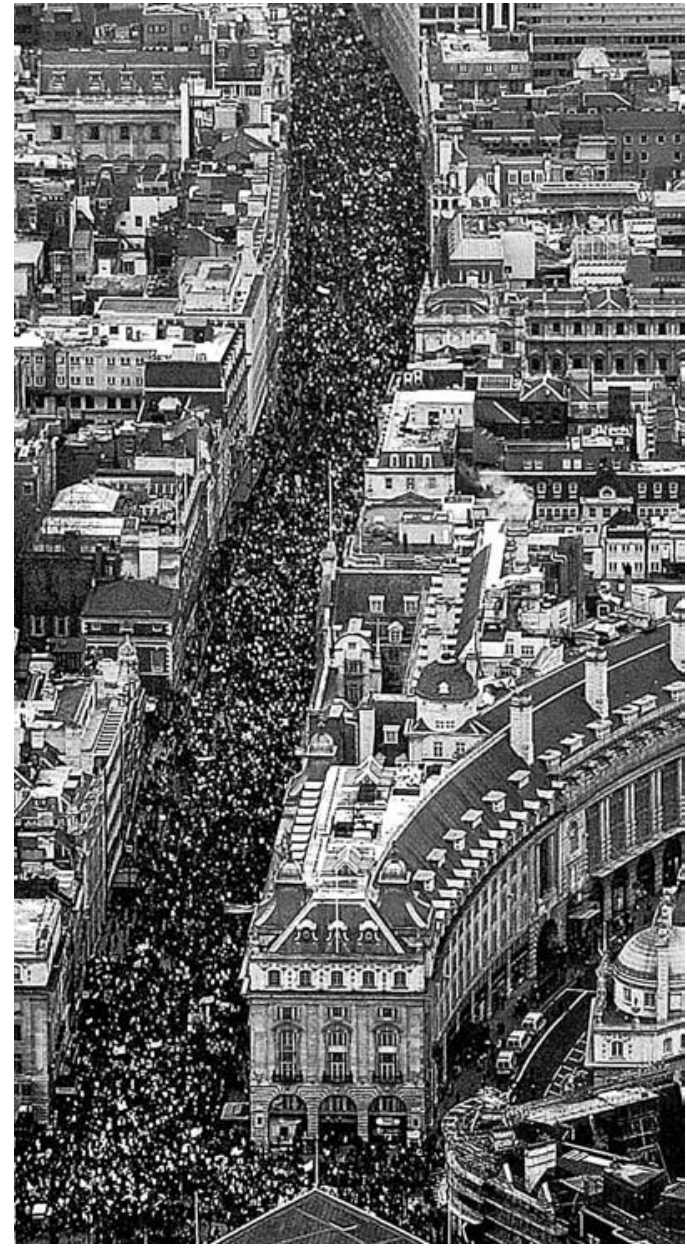

em 1995, David Hare mostra-se atento a alguns pontos importantes da prática teatral de Brecht, embora assuma nesta peça um compromisso muito pessoal entre o teatro político, a reportagem e algumas opções dramatúrgicas convencionais. Com efeito, a peça, repartida em 2 actos, organiza-se em 24 cenas (como as horas de um dia), tem cerca de 40 personagens e os actores (mais de 20) estão todos em palco do princípio ao fim, com duas ou três entradas e saídas por razões muito concretas. Com excepção das figuras centrais, os actores ora são as vozes singulares das personagens que representam, ora estão no papel de narradores / repórteres. A estrutura é claramente em episódios, o diálogo vivo, com réplicas relativamente curtas, e oferece-nos uma visão dos acontecimentos que pretende ser distanciada, mas que é conhecedora da realidade reportada. Há um constante bulício em cena, as marcações são muito visíveis (em redor da mesa, conferenciando, reagrupando as cadeiras, respondendo a perguntas de jornalistas ou em enquadramentos mais domésticos, etc.), o cenário é minimalista e algumas falas são dirigidas explicitamente ao público. É neste ponto que se intromete a vontade de criar momentos de forte empatia, conferindo protagonismo a algumas vozes, como acontece em seis cenas: na primeira, um actor lança os quatro aforismos que parecem conduzir a acção (sendo o primeiro "O Inevitável é o que parecerá acontecer por puro acaso"); a segunda (cena 5) dá voz a um jornalista que não entende os escrúpulos dos ocidentais face a uma guerra contra um reconhecido ditador; nas outras quatro falarão, respectivamente, uma representante da nova orientação dos Trabalhistas para aceitar de forma pragmática erros de cálculo, desde que se considerem boas as intenções (a 9. a), uma intelectual palestiniana que declara ser o seu povo "os judeus dos judeus" (a 13.a), um inglês que em Nova lorque se dá conta da desinformação completa das pessoas relativamente ao que de facto se passa (18.a) e, na cena final, um exilado iraquiano que apela aos seus compatriotas para que tomem em mãos o seu próprio destino.

A visão política que transparecia no espectáculo conferia a Bush (numa excelente criação de Alex Jennings) traços caricaturais, embora ancorados numa descrição exacta dos seus procedimentos. É o caso de certos maneirismos, zonas de silêncio - menos de diplomacia do que de aparente lentidão reactiva -, a obsessão religiosa e uma declarada falta de ductilidade. Outras três figuras políticas mereceram um maior destaque: Tony Blair, Condolezza Rice e Colin Powell. 0 primeiro-ministro inglês, na interpretação excepcional de Nicholas Farrell, era representado positivamente na sua preocupação de se comprometer com o "amigo americano" só para assegurar o roteiro da paz para a Palestina, e mostrava-se aflito com os erros políticos e diplomáticos da Casa Branca, continuando, porém, a ser - contra a esmagadora opinião dos britânicos - o indefectível defensor de Bush na Europa. Se Condolezza Rice (por Adjoa Andoh) surge como a expedita voz forte de Bush, verbalizando o que "pensa" o Presidente, Colin Powell (por Joe Morton) será a figura trágica por ser a única voz discordante naquela Administração, mas cujos conselhos insistentes para evitar a guerra ninguém aceita. Dir-se-á que a sua oposição não foi tão forte que Ihe merecesse a recusa do lugar, embora a história tenha vindo provar agora com a reeleição de Bush em Novembro de 2004 e a sua indisponibilidade para continuar como Secretário de Estado na "nova" administração Bush - que David Hare terá, afinal, tido a intuição mais certa dos equilibrios frágeis que se verificaram em todo este processo. Estranha terá sido, porém, a opção de pôr Condolezza a cantar o belo hino Amazing Grace, porque se é verdade que nesta Conselheira para a Segurança Nacional se poderá identificar a longa caminhada dos afro-americanos que da escravatura saíram para os direitos cívicos (que a direita sempre Ihes negou), a ocasião dramática em que entoa o hino e o lado político que representa dificilmente justificariam esta opção dramatúrgica.

Mas estas contradições são também as regras de um teatro político cada vez mais na agenda do mundo de hoje e que aqui andará próximo do pensar de Piscator: o confronto com o presente, o fascínio de se mostrar a história em marcha. E a isso o público aderiu entusiasticamente.

Pensar que um desafio destes ocupou um Teatro Nacional não deixa de ser uma esperança de resgatar o teatro ao entretenimento fácil ou à procura de devaneios inofensivos. Mesmo que desconfiemos que, como pensava Hare em 1978, um teatro assim não chegue para mobilizar consciências ou alterar radicalmente a situação política e social, como, de resto, se terá visto, nas eleições recentes nos EUA. Mas pode sempre acordar algumas dúvidas.
Manifestação contra a guerra, perto de Piccadilly, 15 de Fevereiro de 2003 fot. First News Ltd. 